\title{
Methodological Principles of the Study of the Philosophical Foundations of Psychological Conceptions of Giftedness
}

\author{
Marina Ivleva \\ Moscow Institute of Psychoanalysis \\ Moscow, Russia \\ E-mail: marinanonna@yandex.ru
}

\section{Mikhail Oseledchik}

Department of Philosophy and Social Sciences Moscow State University of Printing named after I. Fedorov Moscow, Russia

E-mail: balu13@yandex.ru

\author{
Vitaly Ivlev \\ Moscow State Technical University named after N.E. \\ Bauman \\ (National Research University) \\ Moscow, Russia \\ E-mail: vitalijivlev@yandex.ru
}

\author{
Nonna Bagramiants \\ Department of Human Resources \\ Sportmaster \\ Moscow, Russia \\ E-mail: nonnalev@yandex.ru
}

\begin{abstract}
We pose and solve the problem of formulating the basic methodological principles of research of accumulated scientific knowledge about the psychology of giftedness, which is characterized by internal contradictions. The elimination of these contradictions is impossible without comparing and bringing to unity the philosophical foundations of different psychological approaches, which results in the need to address general methodological nature of the problem - to outline the basic principles of the philosophical foundations of the psychological conception of giftedness.
\end{abstract}

Keywords -methodological principles; talent; the theory; the conception; the psychological conception of giftedness; paradigm

\section{INTRODUCTION}

The effectiveness of the work of a teacher or a psychologist for the development of gifted children directly depends on the scientific elaboration of programs and methods used. The validity of the provision is confirmed not only by numerous studies, but also by the facts of failures in the work with gifted children. Psychology of giftedness has long and varied material, which requires the development of theoretical and methodological foundations of its scientific understanding. The absence of such a framework is a major scientific problem that can be solved by studying the process of accumulation of theoretical and methodological assumptions of giftedness research.

The main difficulty in the study of the psychological conception of giftedness (PCG) is related to the heterogeneity of the underlying theoretical and methodological bases and assumptions, and to the point that the facts accumulated cannot be ascribed to one level or hierarchy of psychological reality. Therefore it is necessary to formulate appropriate criteria that will allow us to highlight the structural object of our study - the conception as a form of organising knowledge.

\section{THE PRINCIPLE OF DIFFERENTIATION OF CONCEPTIONS AND THEORIES AS A FORM OF DEVELOPING KNOWLEDGE}

According to the common philosophy and methodology of scientific knowledge definitions, the conception in comparison with the theory is a weaker, minimal form of organization of knowledge [1] [2].

The notions of "conception" and "theory" have much in common and, in certain contexts, can even be used as synonyms. However, the purpose of this study is to differentiate their meanings. The conception refers to the discursive form of research and search activities, which is done either in the form of scientific and theoretical discourse. In some cases (but not necessarily), this may involve empirical verification in the form of free humanitarian discourse, which consists in producing a plurality of consecutive hypothetical constructions.

The theory as a form of knowledge, as opposed to the conception claims to offer a substantially higher level of logical organization, it is designed to give from the logical and methodological point of view a coherent and internally consistent idea about the patterns and significant relationships in a certain field of reality. If the main components of the conception are the concepts, for the theory such basic components are the notions.

Developed (mature) social theory should (ideally) have the following attributes [3]: 
- Reliance on facts, empirical verifiability. However, we should not forget that the fact is an event set by the subject who always explicitly or implicitly bases his view of the world with some of the conceptions according to which he can focus on certain parts of the entire variety of events, and, consequently, on different facts [4].

- The presence of primary explanatory schemes, combined by initial theoretical constructs (categories). Primary explanatory schemes provide a synthesis of empirical data in the general semantic field of theory.

- The presence of the base content model of the studied reality, which includes the basic idea of the theory, the idealized theoretical objects, assumptions and hypotheses that allow with the help of certain logical and methodological schemes, regulators and techniques to build a scientific picture of the reality under analysis.

- The presence of secondary interpretative schemes and other theoretical constructs, i.e. applied models, which are interrelated, and the main idea of the theory, as well as logical and methodological mechanism (the logic and methods of research and exposition), which provides some methods and sequence of the deployment of the conception in the form of a research program.

- The set of new conceptions in relation to other conceptions and theories of the statements and conclusions, including their development and justification (in logical and mathematical models proof).

- A partial formalization of the base content model that allows other researchers to work constructively with the theoretical objects and conclusion, which in contents do not recreate the whole conception and its prerequisites.

None of these criteria is considered to be obligatory for conception, like a general criterion of science. For said theory, it is expressed in the fact that, on one hand, its main provisions should correspond to the empirical basis, emerging and reproducing within certain forms of material and practical activities. On the other hand, the provisions of the theory, the findings and definitions of its concepts should ideally form a logically consistent system which has empirical interpretation, including a broader range of phenomena and processes than those that constitute its original empirical basis. It should also be noted that since psychology refers to the type of social and humanitarian sciences, a specific feature of the psychological theories is, in particular, the feasibility of introducing the concepts by using elements of the genetic method. It is essential to take into account that psychological concepts arise on the basis of the relevant concepts, which, in turn, are created by certain social and cultural conditions and often have a long history of formation within the concepts.
If the conception at a certain stage of its development is transformed into a scientific theory, the process of this transformation appears as the theorization of the conception, while the formation of the conception is the conceptualization of relevant ideas, concepts, values, behavioral patterns. Based on this, we have to separate the conception from the theory and from the amount of nonconceptualized ideological elements which serve as the building blocks for the conception. These elements can be present in almost all spheres of social life, manifest themselves in the people's behavior. Conceptualization is carried out in certain forms of social consciousness, which are associated with scientific or philosophical discourse. Before the emergence of scientific psychology, the formation basis of the conception of giftedness could serve such areas of social consciousness as philosophy and philosophical anthropology, medicine, pedagogics, religion, and art.

The difference between the conception and the theory can be seen in the fact that to the basic functions of the concepton, to which belong description and understanding, in the process of transition to the theory the scientific and explanatory-prognostic functions are added.

It follows from the above that we use the principle of differentiation between the conceptions and theories as the forms of developing knowledge, as well as the principle of unity of the historical, conceptual and logical approaches in the study of the conception of giftedness. This conception can be considered in its development as something dynamic, in contrast to the theory, which is a certain, though an interim result, the product of logical and methodological design of internally consistent amount of scientific knowledge. This proves another accepted in the process of formation of the conception of giftedness research principle the principle of paradigm analysis or approach.

\section{PRINCIPLE OF PARADIGM ANALYSIS OR APPROACH}

On the basis of the analysis carried out by domestic and foreign theoretical studies of giftedness [5], it can be argued that there was formed the study area, in which diverse individual research does not have a unified theoretical framework and principles that facilitate their integration. This could indicate either the absence of a single paradigm, or that the existing paradigm allows the existence on its basis logically inconsistent theories.

The situation in modern psychological science is very similar to the state before Newton physics with regard to its ideas about the nature of light, as described by T. Kuhn in his famous book "The Structure of Scientific Revolutions" [6]. In modern psychology, we see not only the absence of a single approach to the definition of giftedness, but the existing approaches are based on a fundamentally different ontological grounds. A similar situation was observed in physics before Newton. It did not have either a unified theoretical definition of light or a common ontological foundation, as well as common principles of constructing the scientific discourse.

The reason for this was that the theory of light began to form in physics at its preparadigmatic its stage of 
development, long before the science in its development reached a state of "normal" (in the terminology of Thomas Kuhn) science. Normal science is the science which has a developed paradigm. As an example of such science, Kuhn considers physics.

Kuhn distinguishes between "preparadigmatic", "paradigmatic" and "postparadigmatic" periods in the development of science and is talking exclusively about the "normal" sciences. It is clear that psychology is not one of these sciences, at least at this stage of its development. Since its inception in the status of an independent science to this day, psychology does not have a single paradigm that is perceived by the psychologists as a symptom of the permanent crisis of science. In these circumstances, psychologists trying to understand the causes of permanent "crisis" of this science, have a natural temptation to consider this issue in the framework of categorical apparatus developed by T. Kuhn for the analysis of natural (and "normal") sciences. This implies three positions, which define the epistemological status of psychology in a different way.

According to the first position, based on the characteristic that was given to psychology by Kuhn, this science is a preparadigmatic field of knowledge. In other words, the paradigm of knowledge in this area has not yet been formed.

According to the second position, prevalent among psychologists, psychology is a multiparadigmatic science, it has several paradigms ranging from major psychological theories such as behaviorism, cognitivism and psychoanalysis, or, in another version, the positivist and humanistic paradigm.

According to the third position Kuhn's concept, which arose as a result of summarizing the history of the natural sciences, is inapplicable to psychology, which is not a multiparadigmatic or preparadigmatic science but is an extraparadigmatic domain of knowledge.

Based on these estimates by T. Kuhn, the most relevant in relation to psychology is the notion of extraparadigmality. Under this term, we mean the existence of science not only because of the absence of its own single scientific paradigm, but because of the use of external paradigms, i.e. paradigms that have emerged out of this science in other fields of knowledge and, more broadly, of the spiritual life. Outset that this approach implies a broader interpretation of the concept of "paradigm" than that of T. Kuhn. In its original meaning, the word "paradigm" implies literally "an example" or "sample". The specificity of the term "paradigm" by T. Kuhn is that he restricts the scope of using this term, firstly, exclusively to the research in science, and secondly, only to those sciences which produce their own paradigm. It's only on this stage of development of such science, when at least once a paradigm has been developed by this science. Therefore, this term, when used in strict accordance with the definition of $\mathrm{T}$. Kuhn, proves to be not suitable for describing many phenomena and facts of science development and, above all, the social and human sciences, one of which is psychology.
At the same time, nothing prevents us from using having a long history of the concept of "paradigm" in its general sense, specifying this sense in relation to the object of our study. We will speak about the cognitive paradigm as a combination of patterns to set scientific problems and to solve them, which are based on the ideas or assumptions shared by a certain scientific community. Thus, under the scientific community, we understood not all the representatives of the same science (e.g. psychology), and a real community, i.e. scientists, who have scientific communication with each other.

The difference between our concept of the paradigm from that of Kuhn's one can be described by three main points. The first point is common paradigm. According to T. Kuhn's definition of paradigm, it is the same for a science. It must be shared by all its representatives, otherwise the paradigm shift occurs. In our definition, a community it is not a necessary feature of the cognitive paradigm.

The second point is the universal applicability of the concept of "paradigm". According to the definition by $\mathrm{T}$. Kuhn, this concept is not universal, it only applies to a certain type of science - the "normal" science. Our definition suggests a paradigm in relation to any science. The third point is the origin of the paradigm. According to the definition by $\mathrm{T}$. Kuhn, science itself develops its own paradigm. Actually, the paradigm, by T. Kuhn consists of the "achievements" of this science, ie scientific results accepted by all its members. Our definition allows to explore the paradigm which have a non-specific, external origin. The consequence of this is, in particular, the possibility of having a paradigm common to two or more sciences and not only the science but also other forms of knowledge and spheres of social activity. Armed with a modified definition of the paradigm, it is reasonable to go back to the justification of the proposed position of considering psychology as an extraparagigmatic discipline.

The defended thesis is that psychology as its paradigm uses a ready-made, outside paradigm, which is non-specific, socio-cultural in its origin. The best proof of this thesis is the existence of the concept of giftedness. As has been shown in a number of our papers [7] [8], long before the conception has begun to develop in the framework of psychology as a mature science, it already existed in other areas of public consciousness, it evolved to the level of everyday thinking. At certain moments, it became part of the universe. The process of the genesis and development of this conception started long before psychology was identified as an independent science, characterized by its own subject and its own specific research methods. This is understandable because, in the genetic sense, the concept of giftedness is not a specific psychological notion.

The paradigm of psychology is not a product of this science. This paradigm is rooted in social practices and cultural environment, it incorporates both the representations of everyday consciousness and the patterns of philosophical discourse. The content of paradigm contains philosophical foundations of PCG, including ontological, epistemological, socio-anthropological and axiological foundations which in 
their substantial respect are the components of sociocultural paradigm of psychology. In relation to the same PCG, they are non-actualised presuppositions shared by all members of the scientific community who are involved in the development of giftedness subject matter. Here appears the principle of the dialectical unity of ontological, epistemological, socio-anthropological, axiological presuppositions of psychological knowledge about giftedness.

\section{THE PRINCIPLE OF THE DIALECTICAL UNITY OF ONTOLOGICAL, EPISTEMOLOGICAL, SOCIO- ANTHROPOLOGICAL, AXIOLOGICAL PREREQUISITES}

In T. Kuhn's model, the analogues of the philosophical foundations are the "metaphysical parts of paradigms" and the "values." Considering the paradigm as the sets of regulations for scientific group, T. Kuhn defines it as a "disciplinary matrix". It is "disciplinary" because it takes into account the traditional fact that the scientists belong to a particular discipline; it is "matrix" because it is composed of ordered elements of various kinds, each of which requires further specification "[9].

Among the most important components of a disciplinary matrix, T. Kuhn identifies the so-called "symbolic generalizations", "metaphysical parts of paradigms" and "values" [10]. By "symbolic generalizations" he means, in fact, the conceptual structures that make up the framework of the language of science. By "metaphysical parts of paradigm", T. Kuhn means "beliefs in specific models," including both heuristic and ontological models. As for values, by considering the paradigm of "normal" science, $\mathrm{T}$. Kuhn includes into it only axiological focus related to science. The non-specific psychological paradigm may include as its component the non-specific values as well, i.e. the values which refer to the object of science and the subject studied. The influence of this component of the sociocultural paradigm manifests itself in the imminent axiological message of psychological knowledge.

We define the philosophical foundations of the PCG as an essential component of cognitive psychology paradigm, which is a system of ontological, epistemological, socioanthropological, axiological presuppositions of psychological knowledge about giftedness. This paradigm has a socio-cultural nature, it is formed on the basis of existing forms of social consciousness, including philosophy. Since the beginning of psychology as a science, it is included in the public consciousness and actively influences it, thereby exerting influence on its own paradigm (due to the socio-cultural conditioning of psychology). However, the impact of other factors of public consciousness on the paradigm of psychology does not stop.

Thus, the philosophical foundations of psychology in general, and in particular the philosophical foundations of PCG, are a component of the socio-cultural paradigm, they in their development are determined, first, by factors of social consciousness external to psychology, and secondly, since the emergence of psychology by the internal factors of psychological science. Therefore, we can rightly speak of the formation of the philosophical foundations of the PCG long before the beginning of PCG and psychology as a science. Moreover, it is the formation of the philosophical foundations of the PCG that serves as a necessary condition for the emergence of this conception in psychology. In other words, psychological reflection on the phenomenon of giftedness becomes possible only after in the existing sociocultural paradigm the necessary conditions for philosophical reflection on this phenomenon are created, this reflection includes all of the essential characteristics of the phenomenon of giftedness which we identified previously [11].

\section{CONCLUSION}

The task of scientific understanding of numerous and varied materials accumulated in the field of psychopedagogical work with gifted children can be solved by the research and development of theoretical and methodological bases of the systematization and coordination of this material, or the philosophical foundations of the psychological conception of giftedness. The application of the principles of differentiation between a concept and a theory as a form of knowledge development, a principle of unity of historical and conceptual and logical approaches, a principle of paradigmatic study or approach, as well as the principle of the dialectical unity of ontological, epistemological, socioanthropological, and axiological presuppositions of psychological knowledge about giftedness in the study of giftedness conception allowed to make the following conclusions. Modern knowledge about giftedness as a type of knowledge can be considered as a psychological conception of giftedness in contrast to the theory. Structural features of this concept are largely determined by the epistemological status of psychology as an extraparadigmatic science. In contrast to the exact sciences, psychology does not generate a scientific paradigm, but it uses an "external" non-specific cognitive paradigm. This paradigm has a socio-cultural nature and includes the ideological and philosophical components in its content. It is also internally inconsistent and incomplete, allowing the existence of various philosophical concepts and logically inconsistent scientific theories. As for the accumulated by modern psychology the knowledge about giftedness, it is not a unified theory. It is a set of theoretical constructs not always compatible with each other because of the mismatch of the underlying ontological, epistemological, axiological, socio-anthropological presuppositions constituting the philosophical foundations of psychological theory.

Hence, the task to study the formation of the philosophical foundations of the PCG as a real historical process, which began long before the emergence of scientific psychology and flowing in the mainstream of the development of philosophy, not without the influence from other forms of social consciousness, mainly religious, moral, aesthetic and artistic consciousness, partly political consciousness.

The structure of the philosophical foundations of PCG is not the homomorphic reflection of the structure of philosophical knowledge. It is determined, first, by the features of the subject of PCG research - giftedness as a 
sociocultural phenomenon, the system of its essential characteristics, and secondly, epistemological, and methodological and epistemological needs of psychological knowledge. A priori, we can distinguish in the structure of the philosophical foundations of PCG the following components: ontological, axiological, socio-anthropological, epistemological and general methodological. The first three of these components allow, taking into account the specifics of giftedness as a sociocultural phenomenon, to justify its existence as an object of psychological research, to identify its "location" in the system of being, namely social life, as properties, found in a certain axiological perception of the human being, which becomes possible in certain social and historical conditions. Epistemological and general methodological components of the philosophical foundations of PCG allow to justify the possibility of comprehending giftedness by the instruments of psychological science and to develop an adequate method of its scientific investigation.

\section{REFERENCES}

[1] The New Encyclopedia of Philosophy / IP RAS. In 4 v. / Ed. Stepin V.S. - M.: Thought 2001.

[2] Dictionary of Philosophical Terms / Ed. Kuznetsova V.G. - M.: INFRA-M, 2004.

[3] Stepin V.S. Philosophy of Science. Common problems. - M.: Gardariki, 2006. P. 156-208.

[4] Fleck L. Emergence and Development of a Scientific Fact. - M.: Idea-Press, 1999.

[5] Ivleva M.L. Formation of Psychological Conception of Giftedness: Theoretical and Historical Research. - M.: MSTU "MAMI", 2008.

[6] Kuhn T. The Structure of Scientific Revolutions. - M.: Progress, 1975.

[7] Ivleva M.L. Philosophical Foundations of the Psychological Conception of Giftedness. M.: MSTU «MAMI», 2011.

[8] Ivleva M.L., Inozemtsev V.A., Ivlev V.Y., Udovik V.E. Information Society and the Formation of a New Epistemological Paradigm of Modern Science. - M, 2013.

[9] Kuhn T. The Structure of Scientific Revolutions. - M.: Progress, 1975. $198 \mathrm{p}$.

[10] Kuhn T. The Structure of Scientific Revolutions. - M.: Progress, 1975. P. 198-204.

[11] Ivleva M.L. Philosophical Foundations of the Psychological Conception of Giftedness. M.: MSTU «MAMI», 2011. 